\title{
Dominant and recessive mutations define functional domains of Toll, a transmembrane protein required for dorsal-ventral polarity in the Drosophila embryo
}

\author{
David S. Schneider, Kathy L. Hudson, Ting-Yi Lin, and Kathryn V. Anderson \\ Genetics Division, Department of Molecular and Cell Biology, University of California, Berkeley, California 94720 USA
}

\begin{abstract}
The asymmetry of the dorsal-ventral pattern of the Drosophila embryo appears to depend on the ventral activation of the transmembrane Toll protein. The Toll protein is found around the entire dorsal-ventral circumference of the embryo, and it appears to act as a receptor for a ventral, extracellular signal and to then relay that signal to the cytoplasm in ventral regions of the embryo. Three of five recessive loss-of-function alleles of Toll are caused by point mutations in the region of the cytoplasmic domain of Toll that is similar to the mammalian interleukin-1 receptor, supporting the hypothesis that Toll acts as a signal-transducing receptor. Nine dominant gain-of-function alleles that cause Toll to be active in dorsal, as well as ventral, regions of the embryo are caused by mutations in the extracellular domain. Three of the dominant alleles appear to cause the protein to be constitutively active and are caused by cysteine-to-tyrosine changes immediately outside the transmembrane domain. All six of the remaining dominant alleles require the presence of a wild-type transmembrane Toll protein for their ventralizing effect and all encode truncated proteins that lack the transmembrane and cytoplasmic domains.
\end{abstract}

[Key Words: Dorsal-ventral; Drosophila embryo; Toll interleukin-1 receptor]

Received January 7, 1991; revised version accepted February 8, 1991.

Twelve maternally transcribed genes are required for dorsal-ventral pattern formation in the Drosophila embryo (Anderson and Nüsslein-Volhard 1984; Schüpbach and Wieschaus 1989). The products of these genes create a ventral-to-dorsal morphogen gradient by regulating the nuclear translocation of the dorsal protein in a spatially asymmetric manner (Steward et al. 1988; Roth et al. 1989; Rushlow et al. 1989; Steward 1989). In the nuclei, dorsal protein presumably acts as a concentration-dependent transcriptional regulator that activates or represses distinct zygotic target genes in specific regions of the embryo (Rushlow et al. 1987; Roth et al. 1989). To understand the generation of dorsal-ventral asymmetry in the embryo and the mechanisms leading to the production of the nuclear dorsal protein gradient, we are studying the biochemical functions of, and interactions among, the maternal gene products in this pathway.

Among these maternal effect genes, the Toll gene plays a crucial role in defining the spatial organization of the pattern. Embryos produced by females that lack Toll activity are dorsalized, lacking all lateral and ventral pattern elements. Dominant gain-of-function alleles of Toll that result in expansion of ventral pattern elements have been recovered at high frequency, pointing to the impor- tance of Toll in determining the organization of the dorsal-ventral pattern (Anderson et al. 1985b). In addition, among the seven genes for which injection of wild-type cytoplasm can rescue the dorsalized mutant phenotype, only $\mathrm{Toll}^{-}$mutant embryos show no residual dorsalventral asymmetry, with the site of ventral structures defined by the site of deposition of the wild-type gene product (Anderson et al. 1985a). Thus, in these injection experiments, a high local concentration of the Toll product can define the polarity of the dorsal-ventral pattern. In the wild-type embryo, the Toll protein is evenly distributed at the syncytial blastoderm stage, the time of Toll activity (Anderson and Nüsslein-Volhard 1986; Hashimoto et al. 1991), suggesting that the Toll protein is spatially regulated such that it becomes active on the ventral side of the embryo.

The 12 maternal gene products required for dorsalventral pattern formation appear to define a pathway through which information passes from outside the embryo to the nuclei. Two sequenced dorsal-group genes that are known to act genetically upstream of Toll, east$e r$ and snake, encode extracellular-type serine proteases that are present in the extracellular perivitelline space between the plasma membrane and the eggshell (De- 
Lotto and Spierer 1986; Chasan and Anderson 1989; D. Stein and C. Nüsslein-Volhard, pers. comm.; Y. Jin, R. Chasan, and K.V. Anderson, unpubl.). The Toll gene encodes a transmembrane protein found in the plasma membrane (Hashimoto et al. 1988, 1991). Together, both molecular and genetic evidence suggests that Toll occupies a position in the pathway where it could transmit a signal from extracellular upstream gene products to intracellular, downstream gene products, finally giving rise to the nuclear gradient of dorsal protein.

The Toll gene encodes a 1097-amino acid protein that contains a single, membrane-spanning domain (Hashimoto et al. 1988) and has some features of known signaltransducing receptors. The cytoplasmic domain of Toll is similar to the intracellular domain of the human and mouse interleukin-1 receptors (IL-1Rs), (see Fig. 2, below); (Sims et al. 1988, 1989). The 803-amino acid residue extracellular domain, of Toll is composed largely of two blocks of leucine-rich (L-rich) repeats. L-rich repeats of this type have been found in a diverse group of proteins including the transmembrane protein platelet protein glycoprotein $(\mathrm{gp}) \mathrm{lb} \alpha$ and $\beta$, gp IX, and the lutropinchoriogonadotropin receptor (Lopez et al. 1987, 1988; Hickey et al. 1989; McFarland et al. 1989). The Drosophila protein chaoptin, which is composed almost exclusively of L-rich repeats, can mediate homotypic cell adhesion (Krantz and Zipursky 1990), and Toll itself can promote heterotypic cell adhesion (Keith and Gay 1990), providing evidence that this motif defines a protein-protein interaction domain.

An array of ethylmethane sulfonate (EMS)-induced recessive and dominant alleles of Toll that cause a variety of changes in the size and spatial distribution of ventral and lateral structures in the embryo has been isolated (Anderson et al. 1985b; Gerttula et al. 1988; Erdélyi and Szabad 1989). Here we describe the mutations responsible for nine dominant and five recessive alleles of Toll. The mutant sequences define domains of the Toll protein that are essential for its normal activity. In addition, the mutations may define extracellular sites of interaction with proteins that spatially regulate the activity of Toll and intracellular regions that are required for Toll to transmit the signal that controls nuclear localization of the dorsal protein.

\section{Results}

Recessive mutations in Toll alter either the intracellular or extracellular domain of the protein

Each of the recessive Toll alleles analyzed has some residual activity, with a distinctive phenotype and complementation behavior. Four of the five recessive alleles sequenced contained a single base change from the parental chromosome that would cause a single amino acid change (Fig. 1). Three alleles were found to have a mutation in the cytoplasmic domain, and two were found to have mutations in the extracellular domain of the Toll protein.

Females homozygous for $T 7^{\mathrm{r} 26}$ produce strongly dorsal- ized embryos (Anderson et al. 1985b). This allele is slightly temperature sensitive and in some genetic backgrounds causes a dominant dorsalizing phenotype, indicating that it has some antimorphic character. An extracellular mutation was found in $T{ }^{126}$ in the cysteine-containing motif following the first block of L-rich repeats (Fig. 1).

The $T T^{r m 9}$ mutation causes an unusual embryonic phenotype. The embryos are lateralized; both dorsal and ventral structures are absent, and all cells adopt lateral fates (Anderson et al. 1985b). Two nonconservative amino acid substitutions were found in the extracellular domain of $T l^{r m 9}$ in the first and second blocks of leucine repeats (Fig. 1). We have not determined whether one or both changes are required to generate the mutant phenotype.

Three recessive dorsalizing alleles, $T I^{r 444}, T 1^{r B 1}$, and $\mathrm{TT}^{r B 2}$, have mutations in the cytoplasmic domain of the Toll molecule (Fig. 1). The cytoplasmic domain mutations are particularly interesting in light of the sequence similarity between the Toll protein and the IL-1R (Fig. 2) (Hashimoto et al. 1988; Sims et al. 1988, 1989). The extracellular domains of these two proteins are completely different, but the cytoplasmic domains are $26 \%$ identical and $43 \%$ similar in sequence. The two cytoplasmic domains can be aligned from the first residue after the transmembrane domain through the entire 217-aminoacid-residue length of the IL-1R cytoplasmic domain without the introduction of large gaps. The Toll cytoplasmic domain has an additional 68-amino-acid residue tail that is not present in the IL-1R. The three cytoplasmic Toll mutations are located in the region of similarity between the two molecules (Fig. 2). The strongest allele, $T T^{B 2}$, changes a valine found in both Toll and the IL-1 receptor to a methionine. The temperature-sensitive allele $T 1^{r 444}$ changes a phenylalanine (tyrosine in the ILlR) to isoleucine, and the weakest allele, $T 1^{r B 1}$, changes a histidine to a tyrosine, the amino acid residue found in that position in the IL-1R.

\section{Two classes of dominant alleles of Toll change the extracellular domain}

Females carrying any of the 12 dominant alleles of Toll in trans to a wild-type allele produce ventralized embryos in which the ventral and lateral pattern elements are expanded at the expense of dorsal structures. The dominant ventralizing alleles of Toll fall into two genetic classes that differ in their requirement for a wildtype allele of Toll. Females carrying a class I allele $|T|^{1}$, $T 1^{9 Q}, T 1^{10 b}$ ) in trans to a null allele of Toll produce ventralized embryos. In contrast, females carrying a class II allele $\left(T 1^{84 c}, T 1^{5 B}, T 1^{D B 1}, T 1^{D B 2}, T 1^{D B 3}, T 1^{2 b}, T 1^{3 c}, T 1^{201}\right.$, $T I^{18 a}$ ) in trans to a null allele of Toll produce dorsalized embryos, like females that lack all Toll activity (Anderson et al. 1985b; Hudson 1989|. Class II alleles also resemble null alleles in that they lack the Toll activity required for zygotic viability (Gerttula et al. 1988; Hudson 1989). None of the class I alleles are temperature sensitive, but two of the class II alleles $\left(\left.T\right|^{D B 1}\right.$ and $\left.T 1^{2 b}\right)$ 
A

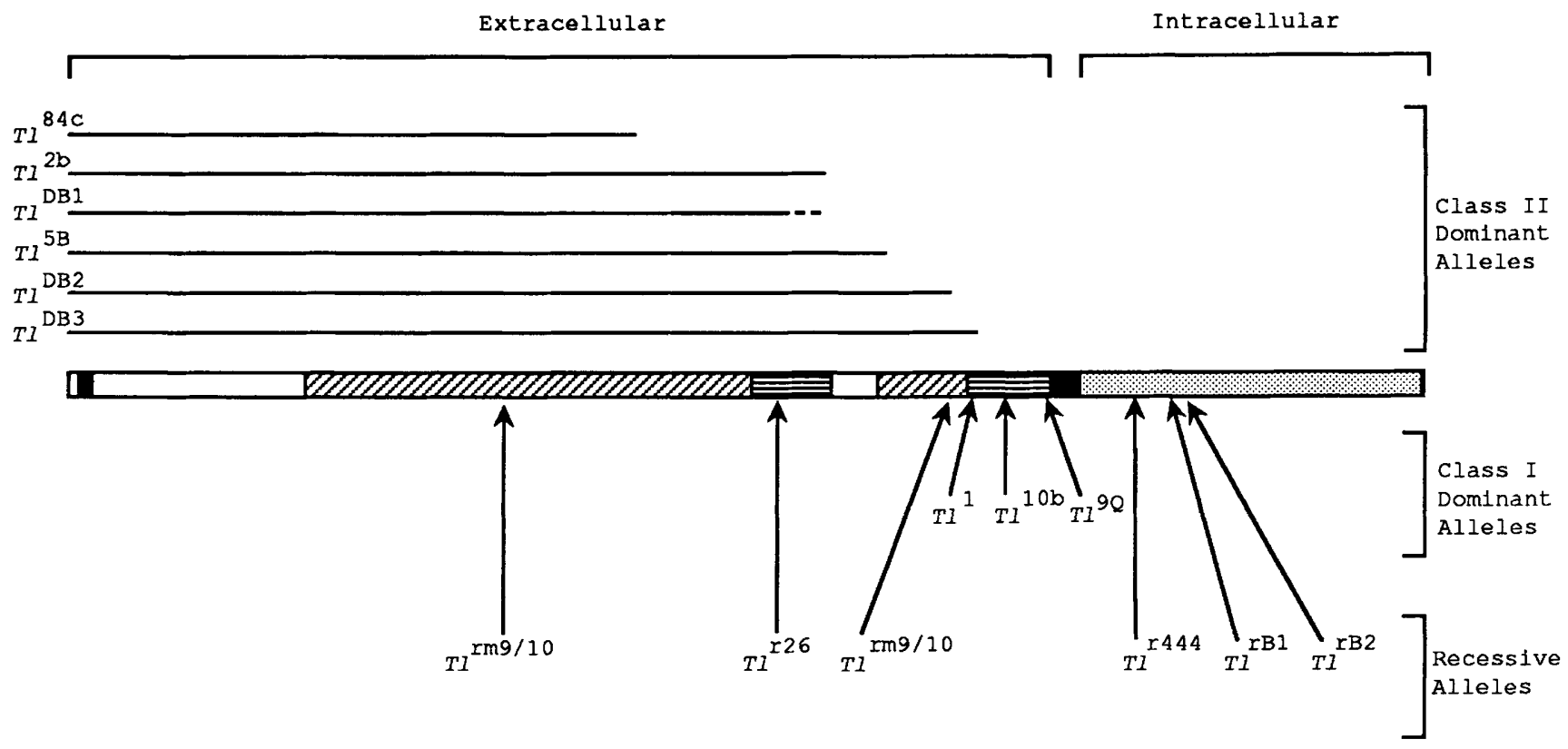

B

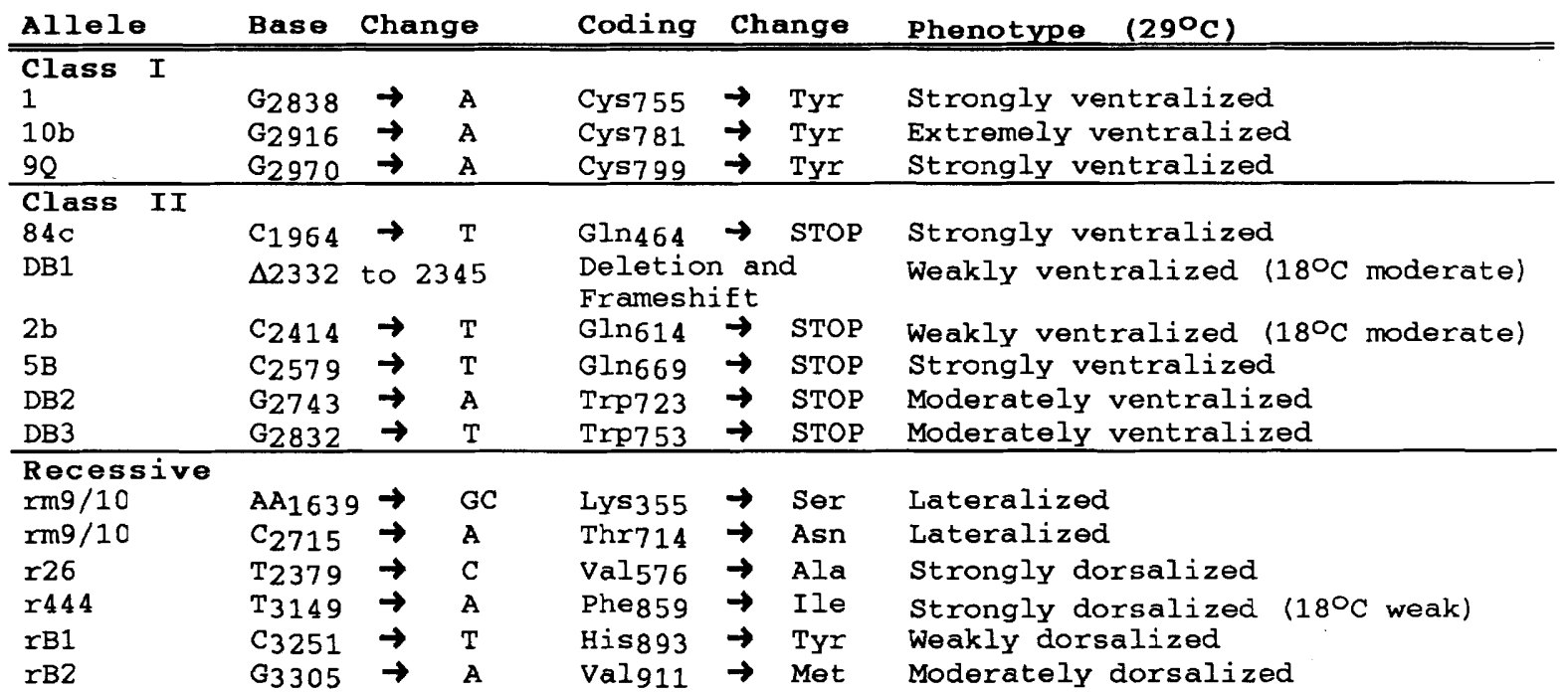

Figure 1. Summary of dominant and recessive Toll mutations. $(A)$ The open reading frames of the class II dominant alleles are depicted by solid lines. The dotted line in $T l^{D B 1}$ indicates the 33-amino acid residue tail that follows the 11 -bp deletion in this allele. The locations of the mutations in the class I dominant alleles and the recessive alleles are indicated by arrows. Hatched areas indicate L-rich repeats; solid areas indicates signal sequence and the transmembrane domain; horizontal lined areas denote terminal flanking domains; the stippled area denotes the cytoplasmic domain. $(B)$ The mutations listed are the changes seen in the coding strand of the Toll gene. Expanded mesoderm is the most extreme ventralized phenotype, with most cells contributing to the most ventral pattern element, the mesoderm; if any cuticle is present, it is ventral cuticle. Strongly ventralized embryos have circumferential ventral denticle bands and no dorsal hairs. Moderately ventralized embryos have expanded ventral denticle bands but retain some dorsal hairs; weakly ventralized embryos have normal ventral denticle belts and slight head and tail defects. Strongly dorsalized (D0) (Anderson et al. 1985b) embryos have circumferential dorsal hairs and no ventral denticles or filzkörper. Moderately dorsalized (D1) embryos have expanded fields of dorsal hairs and filzkörper but no ventral denticles. Weakly dorsalized (D2) embryos have narrowed ventral denticle belts, a field of dorsal hairs, and filzkörper. Lateralized embryos have circumferential ventral denticles but no mesoderm or dorsal hairs. The allele $T l^{r m 10}$ has the same phenotype as $T I^{r m 9}$ and was isolated in the same screen (Rice 1973), which led Rice et al. to propose they could represent duplicates of a single mutation. We found that $T^{7^{m} m 10}$ contained both changes found in $T l^{\mathrm{rm} 9}$ and conclude that these two alleles arose as a single event. 


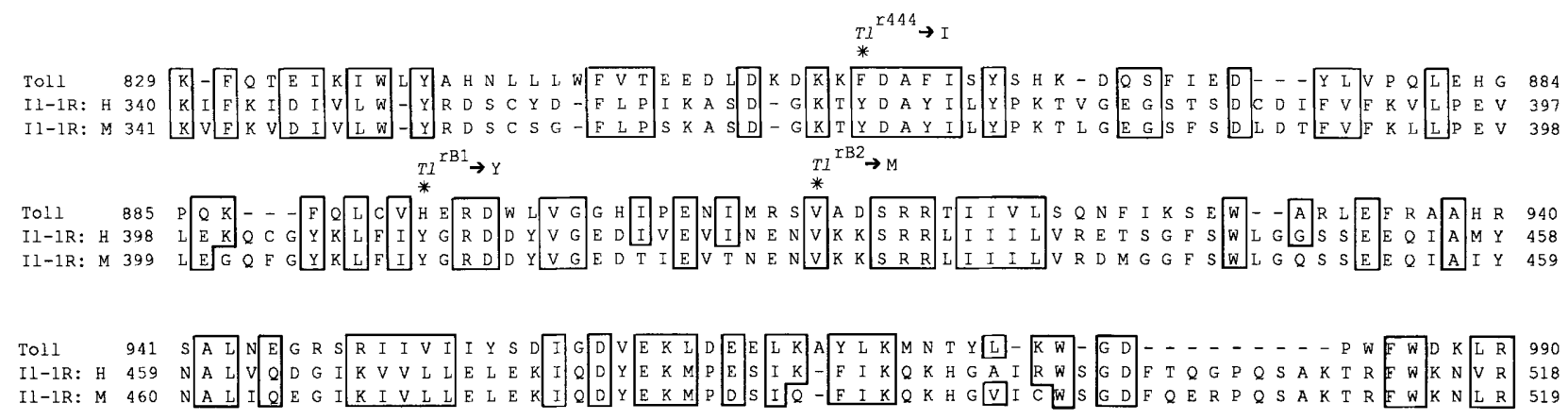

Tol1 991 F A L D H R R R V V GNA I G N G A D I K T A L R G S T D D K L E L I I K P S P V T 1029

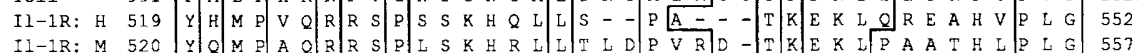

Figure 2. Toll and IL-1R sequence similarity. The sequence of the cytoplasmic domain of Toll is aligned with the cytoplasmic domains of the human and mouse IL-1Rs (IL-1R H and IL-1R M, respectively). Similarities between the cytoplasmic domain of Toll and the IL-1R are boxed. Toll has an additional 68 amino acids in its cytoplasmic domain following the region of similarity. Amino

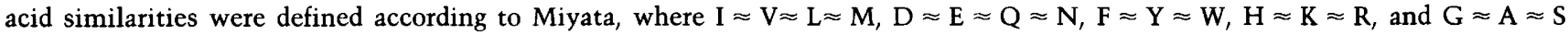
$\approx \mathrm{T} \approx \mathrm{P}$ (Miyata et al. 1979). The amino acid changes found in the cytoplasmic domain of Toll alleles are marked.

are cold sensitive, producing more severe phenotypes at $18^{\circ} \mathrm{C}$ than at $29^{\circ} \mathrm{C}$ (Fig. 3C,D). Class I and class II alleles also differ in their dependence on upstream genes. Double-mutant females that lack the activity of genes upstream of Toll and carry a class I Toll allele produce embryos that make ventral or lateral structures in a dorsoventrally symmetric pattern, whereas double-mutant flies carrying class II alleles of Toll and upstream mutations produce dorsalized embryos (Anderson et al. 1985b; K.V. Anderson, unpubl.). In summary, class I alleles of Toll are cis active and partially independent of the activity of upstream genes, whereas class II alleles are cis inactive, can alter the activity of the wild-type Toll product in trans, and require upstream genes for activity.

In general, the class I alleles produce more strongly ventralized phenotypes than most class II alleles, although the range of phenotypes overlaps. The most extreme ventralized phenotype is seen in embryos laid by mothers carrying the class I allele $T 1^{10 b}$ (Erdélyi and Szabad 1989). In these embryos the most ventrally derived tissue, the mesoderm, is expanded and laterally derived epidermal structures are either absent or greatly reduced (Hudson 1989). The ventralized phenotypes of embryos produced by mothers carrying the class I alleles $T 1^{1}$ or $T l^{9 Q}$ or the class II alleles $T 1^{84 c}$ or $T l^{5 B}$ are similar (Fig. 3B) (Anderson et al. 1985b). Females carrying one of these four alleles produce ventralized embryos with expanded ventral epidermis and the complete loss of dorsal epidermis, but no expansion of the mesoderm. The other class II alleles cause a weaker ventralization of the embryonic pattern, with some dorsal pattern elements still present. The weakest phenotype is caused by the coldsensitive allele $T I^{D B 1}$; at $29^{\circ} \mathrm{C}, 50 \%$ of the embryos hatch into larvae and the remainder do not undergo head involution and may not shorten the germ band (Fig. 3D).

Nine of the dominant alleles were sequenced, and all contained mutations in the extracellular domain of the
Toll molecule (Fig. 1). The sequence changes found in the dominant alleles fall into two molecular classes that coincide with the two genetically defined classes.

Each of the class I alleles changed a cysteine to a tyrosine in the sequence after the second block of L-rich repeat domain, immediately adjacent to the transmembrane domain (Fig. 1). This clustering of mutations prompted us to examine the carboxy-terminal flanking sequences of other L-rich repeat-containing proteins more closely. In Toll, both blocks of L-rich repeats are followed by a cysteine-containing motif, which is also found in a subset of proteins that have extracellular $L$ rich repeats including L-rich glycoprotein (Takahashi et al. 1985), the platelet transmembrane proteins gp $1 \mathrm{~b} \alpha$ and $\beta$, gp IX (Lopez et al. 1987, 1988; Hickey et al. 1989), and the lutropin-choriogonadotropin receptor (McFarland et al. 1989). We found that the similarity between these motifs extends further than described previously (Hickey et al. 1989; Keith and Gay 1990) and that the motifs contain four, rather than only two, conserved cysteine residues (Fig. 4). Each of the three class I alleles replaced one of the four cysteine residues in this motif with a tyrosine residue (Fig. 4).

In each of the six class II alleles sequenced, premature stop codons or small deletions that introduced premature stop codons were found (Fig. 1). The truncated polypeptides produced by these alleles would be from 464 to 753 amino acid residues in length and would include one or both blocks of L-rich repeats. None of the truncated proteins would contain the transmembrane domain. No simple relationship between the length of a truncated class II polypeptide and its phenotypic strength has emerged. For instance, the two strongest class II Toll alleles, $T I^{5 B}$ and $T l^{84 c}$, encoded truncated polypeptides of very different lengths.

Protein blots confirmed that $T l^{\text {classII }} / T l^{+}$heterozygotes synthesized both full-length and truncated Toll 

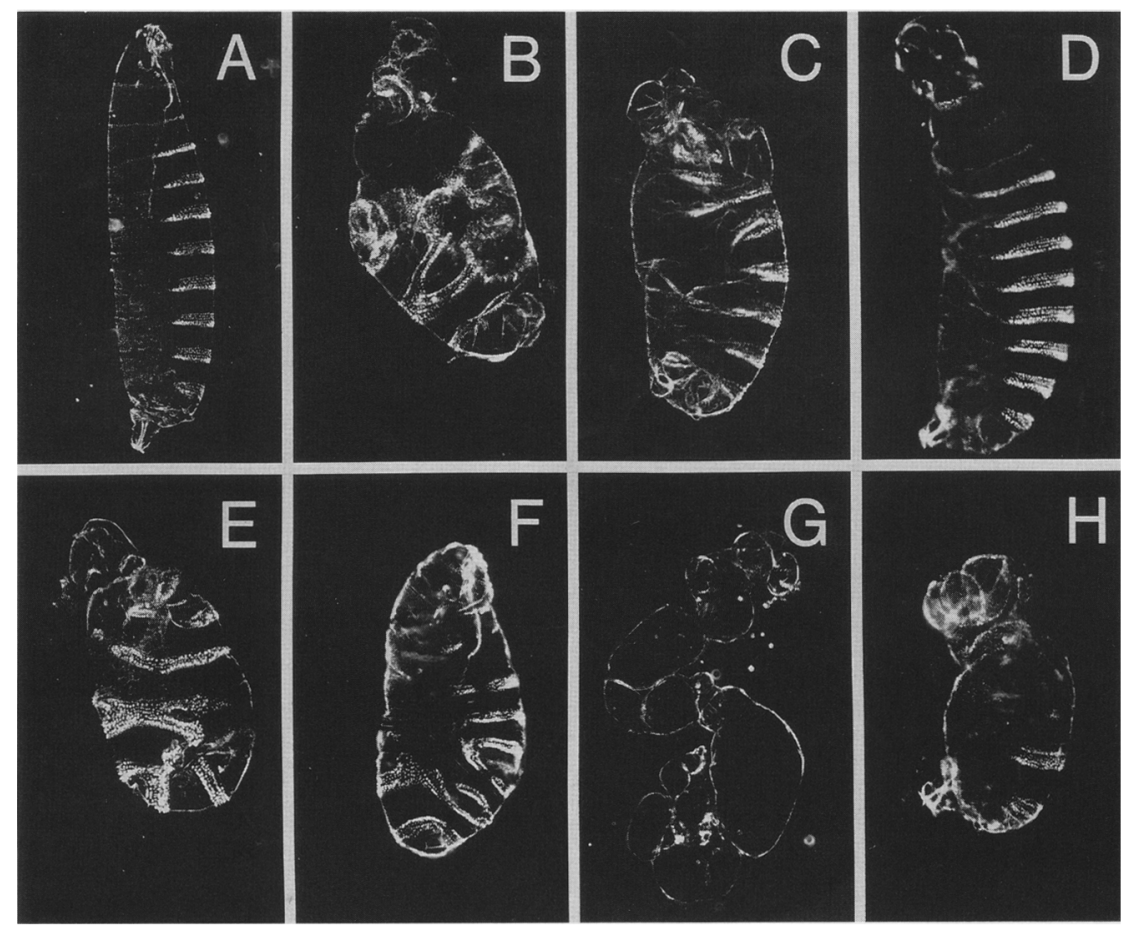

Figure 3. Cuticular phenotypes produced by dominant ventralizing Toll alleles and by injection of dominant allele transcripts. $(A)$ Wild-type, first-instar larva. $(B)$ The cuticle of a strongly ventralized embryo produced by a $T 7^{84 c} / \mathrm{TM} 3$ female. $(C)$ The cuticle of a moderately ventralized embryo produced by a $T 1^{D B 1} / \mathrm{TM} 3$ female at $18^{\circ} \mathrm{C}$. $(D)$ The cuticle of a weakly ventralized embryo produced by a $T l^{D B 1} / \mathrm{TM} 3$ female at $29^{\circ} \mathrm{C}$. $(E)$ The cuticle of a wild-type embryo injected dorsally at $25 \%$ egg length with a transcript encoding a $T 7^{\text {trunc1 }}(66 \mu \mathrm{g} / \mathrm{ml})$. Both head and tail structures are ventralized. $(F)$ The cuticle of a wild-type embryo injected at $25 \%$ egg length on the dorsal surface with the class I $T 1^{10 b} \mathrm{cDNA}$ transcript $(66 \mu \mathrm{g} / \mathrm{ml})$. Only the posterior end of the embryo was ventralized in these injections. (G) The cuticle of a strongly dorsalized embryo produced by a $e a^{4} / e a^{5022 \times X 1}$ female. $(H)$ The cuticle pattern of an embryo produced by an $e a^{4} / e a^{5022 \times X 1}$ female that was injected with a $T l^{10 b}$ transcript at $25 \%$ egg length. This embryo differentiated both the dorsolaterally derived filzkörper and the ventrolaterally derived ventral denticle belts of the sixth, seventh, and eighth abdominal segments.

proteins (Fig. 5). The sizes of the observed proteins were consistent with the sizes predicted from their sequences. The truncated proteins examined were all $\sim 25 \%$ as abundant as the full-length Toll protein, perhaps because they are not as stable as the transmembrane protein.

\section{Injection of dominant allele transcripts can ventralize the embryonic pattern}

To test whether the coding changes found in the dominant alleles were responsible for the mutant phenotypes, we assayed the activity of both class I and class II mutant transcripts injected into wild-type embryos. This assay relied on the ability of injected transcripts of a fulllength Toll cDNA to rescue the dorsalized phenotype of embryos laid by $\mathrm{Tl}^{-}$females (C. Hashimoto, unpubl.). Injection of high concentrations of wild-type transcripts into wild-type embryos never produced a ventralizing phenotype (Table 1).

We replaced segments of the Toll cDNA construct with restriction fragments containing the point mutations of class I dominant alleles and assayed the activity of transcripts of mutant alleles by injection into cleavage-stage, wild-type embryos (Table 1). Transcripts con- taining the $T l^{1}$ or $T l^{10 b}$ cysteine-to-tyrosine changes caused ventralization of the embryonic pattern, confirming that these changes are sufficient to produce a dominant ventralizing phenotype (Fig. 3F).

The extent of ventralization produced by the class I transcripts depended on the concentration of the injected transcripts. Injection of high concentrations $(>66 \mu \mathrm{g} / \mathrm{ml})$ of $T 1^{10 b}$ and $T l^{1}$ (Table 1) transcripts into wild-type embryos induced the formation of local cup-shaped invaginations at the time of gastrulation at the site of deposition (Table 1). We believe that these local furrows correspond to local mesodermal invaginations. Embryos that had large local invaginations differentiated to have large holes in their cuticles, with only ventral cuticular structures present in the surrounding cuticle. We interpreted these embryos as having expanded mesoderm, similar to embryos produced by females carrying the $T 1^{10 b}$ allele. Injections of lower concentrations $(13 \mu \mathrm{g} / \mathrm{ml})$ of $T 1^{10 b}$ and $T 1^{1}$ transcripts produced more weakly ventralized embryos that resembled those produced by $T l^{1}$ females, with ventral denticle bands encircling the circumference of the larval cuticle. Thus, although $T 1^{10 b} /+$ females produce more strongly ventralized embryos than $T 1^{1} /+$ females, the products of both $T 1^{10 b}$ and $T 1^{1}$ caused an 


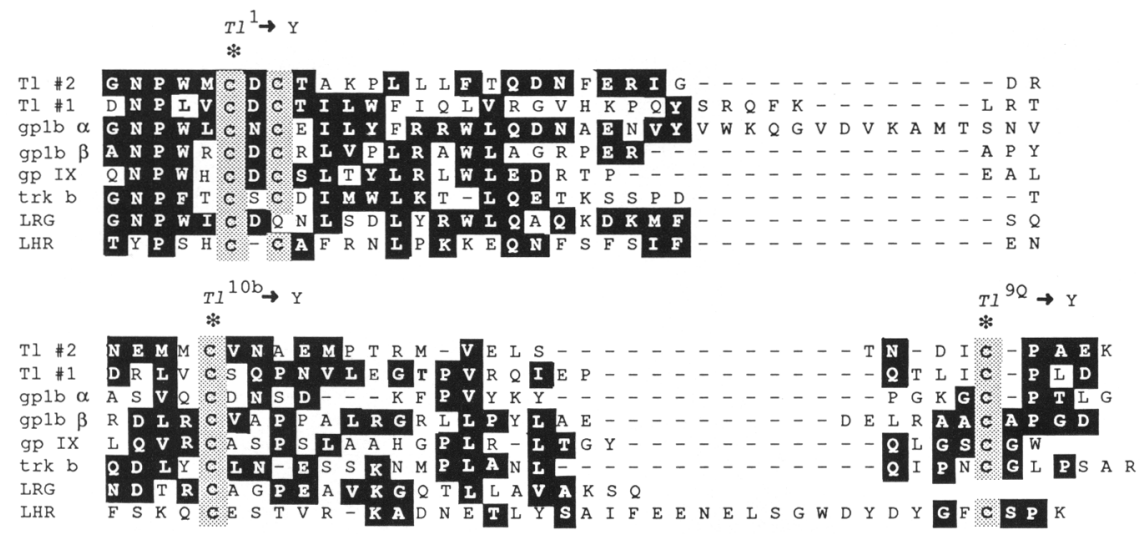

Figure 4. L-rich repeat terminal-flanking sequence similarity. The sequences of the regions carboxy-terminal to the blocks of leucine repeats in the extracellular domain in the Toll protein are aligned with leucine repeat carboxy-terminal-flanking sequences found in human blood platelet glycoprotein $\mathrm{lb} \alpha$ and $\beta$ (gplb $\alpha$ and $\beta$ ) (Lopez et al. 1987, 1988), human blood platelet glycoprotein IX (gp IX) (Hickey et al. 1989), the protein tyrosine kinase receptor trk b (Klein et al. 1989), L-rich glycoprotein (LRG) (Takahashi et al. 1985), and the lutropin receptor (LHR) (McFarland et al. 1989). Amino acid residues are grouped on the basis of similarities between their physical

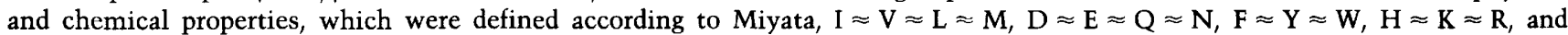
$\mathrm{G} \approx \mathrm{A} \approx \mathrm{S} \approx \mathrm{T} \approx \mathrm{P}$ (Miyata et al. 1979). Similar amino acids are shown in white with a black background. The four cysteine residues found in these repeats are highlighted with a dotted background. The mutations responsible for the dominant phenotypes of class I Toll alleles are in the second Toll terminal repeat at the positions shown.

expansion of the ventrally derived mesoderm at high concentrations and at lower concentrations expanded the laterally derived ventral epidermis without detectably expanding the mesoderm.

When wild-type Toll mRNA is injected into $\mathrm{Tl}^{-}$embryos the dorsal-ventral pattern is rescued along onethird to one-half of the anterior-posterior length of the embryo (Anderson et al. 1985a; C. Hashimoto, unpubl.). The ventralizing effects produced by injection of $T 1^{1}$ or $T l^{10 b}$ transcripts into wild-type embryos were also spatially restricted. Local invaginations at the site of injection were seen when the transcripts were deposited either dorsally or ventrally at the periphery of the embryo. When the transcripts were placed dorsally, a furrow in-

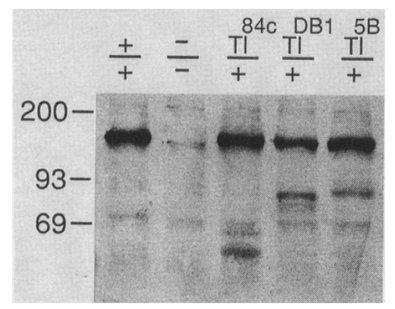

Figure 5. Class II allele protein expression. Extracts of 0- to 4-hr embryos were separated on $7.5 \%$ polyacrylamide gels and transferred to nitrocellulose. Blots were probed with a rabbit polyclonal antibody raised against the amino-terminal domain of Toll (Materials and methods). The product of $T 1^{84 c}$ migrates at $63 \mathrm{kD}$, the product of $T 1^{D B 1}$ at $82 \mathrm{kD}$, and the product of $T T^{5 B}$ at $84 \mathrm{kD}$, the same order of size predicted from the sequences. Each truncated product migrates $\sim 10 \mathrm{kD}$ larger than predicted from its sequence, probably due to glycosylation. Wild-type Toll protein is glycosylated and therefore migrates at $135 \mathrm{kD}$ rather than the $125 \mathrm{kD}$ predicted from the open reading frame $(\mathrm{Hash}$ imoto et al. 1991). vaginated at that site $\sim 2$ min before the invagination of the ventral furrow. No interference with the invagination of the normal ventral furrow was detected. When the transcripts were injected ventrally, a cup-shaped invagination at the injection site slightly preceded, and then appeared to be superimposed on, normal ventral furrow invagination. Injection at $25 \%$ egg length $10 \%$ egg length $=$ posterior pole $/$ prevented germ-band extension but did not affect the dorsal-ventral position of the cephalic fold $(67 \%$ egg length). Larval cuticles of embryos injected at $25 \%$ egg length frequently had wild-type head structures but ventralized posteriors (Fig. 3F). No clear differences were seen in the cuticular patterns between embryos injected ventrally and those injected dorsally.

To test the activity of transcripts encoding truncated products like the class II alleles, we synthesized a Toll cDNA ( $\left.T^{\text {trunc1 }}\right)$ that has a stop codon 5 amino acid residues amino-terminal to that found in $T T^{5 B}$. Injection of high concentrations $(330 \mu \mathrm{g} / \mathrm{ml})$ of a $T 1^{\text {trunc1 }}$ transcript into wild-type embryos at any dorsal-ventral position caused a moderate ventralization of the embryonic pattern, with expanded ventral denticle bands and the loss of some dorsal pattern elements, but some dorsal structures were always differentiated (Fig. 3E). No local ventral furrow was ever induced in these injections (Table 1). In contrast with the local effects seen with class I transcript injections, when the $T 1^{\text {trunc1 }}$ transcript was injected at $25 \%$ egg length, the cephalic fold was shifted to the dorsal side of the embryo and germ-band extension was blocked. Both head and tail cuticle patterns were ventralized in these embryos (Fig. 3E). The global ventralization produced by class II, but not class I, transcripts suggests that the class II, but not the class I, proteins diffuse throughout the extracellular perivitelline space of the embryo. 
Table 1. Phenotypes of embryos injected with transcripts encoding dominant Toll alleles

\begin{tabular}{|c|c|c|c|c|c|c|c|c|c|c|}
\hline \multirow[b]{2}{*}{ Transcript } & \multirow[b]{2}{*}{ Recipient } & \multirow[b]{2}{*}{$\begin{array}{l}\text { Concentration } \\
(\mu \mathrm{g} / \mathrm{ml})\end{array}$} & \multirow[b]{2}{*}{$\begin{array}{l}\text { Injection } \\
\text { position }\end{array}$} & \multirow{2}{*}{$\begin{array}{l}\text { Local } \\
\text { furrow } \\
(\%)\end{array}$} & \multirow[b]{2}{*}{$n_{\mathrm{g}}$} & \multicolumn{4}{|c|}{ Differentiation pattern (\%) } & \multirow[b]{2}{*}{$n_{\mathrm{c}}$} \\
\hline & & & & & & hatch & $\mathrm{FK}+\mathrm{VD}$ & VD & $\begin{array}{l}\text { mes. } \\
\text { exp. }\end{array}$ & \\
\hline$T l^{10 b}$ & wild type & 330 & dorsal & 82 & 49 & 0 & 2 & 10 & 88 & 21 \\
\hline$T 1^{10 b}$ & wild type & 330 & ventral & 90 & 52 & 0 & 5 & & 95 & 47 \\
\hline$T I^{10 b}$ & wild type & 66 & dorsal & 21 & 68 & 4 & 13 & 34 & 49 & 63 \\
\hline$T 1^{10 b}$ & wild type & 66 & ventral & 78 & 81 & 20 & 17 & 17 & 46 & 81 \\
\hline$T I^{10 b}$ & wild type & 13 & dorsal & 0 & 47 & 48 & 21 & 21 & 12 & 18 \\
\hline$T l^{10 b}$ & wild type & 13 & ventral & 11 & 18 & 50 & 28 & 11 & 11 & 44 \\
\hline$T l^{1}$ & wild type & 200 & dorsal & 76 & 46 & & 30 & 23 & 47 & 47 \\
\hline$T 1^{1}$ & wild type & 200 & ventral & 52 & 46 & & 45 & 12 & 43 & 51 \\
\hline$T l^{1}$ & wild type & 40 & dorsal & 10 & 10 & & 73 & 22 & 5 & 40 \\
\hline$T 1^{1}$ & wild type & 40 & ventral & 0 & 11 & & 92 & 4 & 4 & 26 \\
\hline$T l^{\text {trunc1 }}$ & wild type & 330 & dorsal & 0 & 20 & 0 & 18 & 82 & & 25 \\
\hline$T 7^{\text {trunc1 }}$ & wild type & 330 & ventral & 0 & 25 & 4 & 35 & 61 & & 29 \\
\hline $\mathrm{Tl}^{+}$ & wild type & 1000 & dorsal & 0 & 42 & 100 & & & & 33 \\
\hline $\mathrm{Tl}^{+}$ & wild type & 1000 & ventral & 0 & 37 & 100 & & & & 21 \\
\hline
\end{tabular}

\begin{tabular}{|c|c|c|c|c|c|c|c|c|c|c|}
\hline & & & & & \multicolumn{5}{|c|}{ Differentiation pattern $(\%)$} & \\
\hline & & & & & no FK & FK & $\mathrm{FK}+\mathrm{VD}$ & VD & $\begin{array}{l}\text { mes. } \\
\text { exp. }\end{array}$ & \\
\hline$T 1^{10 b}$ & $\mathrm{Tl}^{-}$ & 330 & 80 & 35 & & 9 & & & 91 & 11 \\
\hline$T 1^{10 b}$ & $T 1^{-}$ & 66 & 64 & 44 & & & 12 & & 88 & 16 \\
\hline$T 1^{10 b}$ & $\mathrm{Tl}^{-}$ & 13 & 71 & 51 & & 2 & 38 & 6 & 54 & 48 \\
\hline$T l^{10 b}$ & $T 1^{-}$ & 2 & 0 & 46 & 15 & 70 & 15 & & & 27 \\
\hline$T 1^{10 b}$ & $T l^{-}$ & 0.4 & & & 100 & & & & & 17 \\
\hline$T l^{10 b}$ & $e a^{-}$ & 330 & 92 & 25 & & & 4 & 54 & 42 & 24 \\
\hline$T 1^{10 b}$ & $e a^{-}$ & 66 & 72 & 75 & & 4 & 51 & 20 & 25 & 59 \\
\hline$T 1^{10 b}$ & $e a^{-}$ & 13 & 0 & 58 & 6 & 50 & 38 & 6 & & 18 \\
\hline$T 1^{1}$ & $\mathrm{Tl}^{-}$ & 200 & 87 & 137 & & & & & & 0 \\
\hline$T l^{\operatorname{truncl}}$ & $T 1^{-}$ & 2000 & 0 & 41 & 100 & & & & & 8 \\
\hline$T T^{\operatorname{trunc1}}$ & $e a^{-}$ & 330 & 0 & 65 & 100 & & & & & 11 \\
\hline
\end{tabular}

Local furrow refers to the formation of a local mesoderm invagination during gastrulation at the site of injection. The columns headed $n_{\mathrm{g}}$ and $n_{\mathrm{c}}$ record the number of embryos observed at gastrulation or the number of larval cuticles counted, respectively. Embryos that did not hatch but did not have defects in dorsal-ventral pattern formation are not included here. Hatching was not scored for $T 1^{1}$ injections. Cuticles recorded in the FK column were moderately dorsalized and contained only dorsolaterally derived filzkörper but not the more ventrally derived ventral denticles. Cuticles recorded in the FK + VD column contained filzkörper material and some ventral denticles. In injections into wild-type embryos the FK + VD column includes cuticles that were moderately ventralized. For injections into dorsalized embryos, the FK + VD column lists both moderately dorsalized, essentially wild-type and moderately ventralized cuticles, which could not be unambiguously distinguished from one another. Cuticles recorded in the VD column contained ventral denticles but no filzkörper material and, therefore, were more strongly ventralized than those in the FK + VD column. Cuticles recorded in the mes. exp. (mesoderm expanded) column contained larges holes in their cuticles, which resemble those found in extremely ventralized embryos in which the mesoderm has expanded; only ventral cuticle was seen surrounding the holes. Transcripts were injected onto the dorsal side of $\mathrm{TI}^{-}$or $e a^{-}$embryos.

We also assayed the activity of the dominant transcripts injected into dorsalized embryos that lacked the activity of Toll or the upstream dorsal group gene easter (ea) (Table 1). At an appropriate concentration, injection of class I transcripts near the periphery of embryos produced by $T^{-}$females or $e a^{-}$females promoted the development of a normal, asymmetric dorsal-ventral pattern (Fig. $3 \mathrm{H}$ ). In both kinds of recipient, the most ventral structures developed at the site of RNA deposition. The dose-response curve for rescue was very steep, with high concentrations of transcript ventralizing the embryos, and only a limited concentration range generating a wild-type pattern (Table 1). Five times more dominant Toll RNA was required to rescue lateral and ventral structures in $\mathrm{ea}^{-}$embryos than in $\mathrm{Tl}^{-}$embryos, suggesting that the $e a^{+}$activity present in the $\mathrm{TI}^{-}$embryo potentiates the activity of the product of the dominant allele. As expected from the cis inactivity and upstream gene dependence of the class II alleles, injection of class II transcripts into embryos produced by $\mathrm{Tl}^{-}$and $\mathrm{ea}^{-}$ 
females did not rescue any lateral or ventral structures (Table 1).

\section{Discussion}

Our current hypothesis is that the Toll protein either directly transduces a signal across the plasma membrane of the embryo or is part of a signal transduction complex. To investigate this hypothesis, we have sequenced $\mathrm{mu}$ tant Toll alleles that cause well-defined changes in the embryonic dorsal-ventral pattern. The sequence changes define functional domains of the Toll protein that are consistent with the idea that it acts as a receptor for an extracellular, spatially asymmetric signal and passes on a signal through its cytoplasmic domain. Recessive mutations that lower the activity of Toll alter either the extracellular or cytoplasmic domains of the protein. Dominant gain-of-function alleles, which cause Toll to be active in dorsal as well as ventral parts of the embryo, are all caused by mutations in its extracellular domain. The two genetic classes of dominant Toll alleles correspond to two distinct classes of molecular lesions, identifying two regions of the extracellular domain that are of particular importance in controlling the activity of the Toll protein.

\section{Class I dominant Toll alleles encode constitutively active products}

The class I dominant alleles define the juxtamembrane cysteine-containing motif adjacent to the L-rich repeats as a domain that can control the activity of the Toll molecule. The 18 extracellular cysteine residues in Toll do not form disulfide bonds with other proteins (Hashimoto et al. 1991), suggesting that the cysteines changed in these alleles normally participate in intramolecular disulfide bonds. The L-rich repeat carboxy-terminal flanking sequence of L-rich glycoprotein contains only two cysteine residues that form an intramolecular disulfide bond (Takahashi et al. 1985). The pattern of sequence similarity between the proteins suggests that disulfide bonds form between Cys 1 and Cys 3 and between Cys 2 and Cys 4 in this domain of Toll. The conformational changes that lead to abnormal activity of class I Toll alleles could be due either to the substitution of bulky tyrosine residues for cysteine residues or to interference with normal disulfide bond formation. Both factors may be important. We predict that the $T l^{10 b}$ and $T 1^{1}$ mutations disrupt the same disulfide bond, but they do not cause identical phenotypes.

Like Toll, the Caenorhabditis elegans lin-12 gene encodes a transmembrane protein that is believed to function as a signal transducer (Yochem et al. 1988). Dominant mutations of 1 in-12 that increase the activity of the protein change single extracellular amino acids adjacent to the transmembrane domain /Greenwald and Seydoux 1990). This suggests that although these two proteins share no sequence homology, the conformation of the region just outside the transmembrane domain may be important in defining the activity of the cytoplasmic do- mains of both Toll and lin-12. In addition to producing similar mutant phenotypes, these domains may also be important in regulating the activity of the wild-type proteins. The similar activity of these two domains in Toll and lin-12 suggests that extracellular juxtamembrane domains could have similar functions in other signal-transducing molecules.

Because the class I alleles are active in the absence of upstream genes, it is likely that the class I alleles of Toll send a constitutive signal to the cytoplasm at all dorsalventral positions. The injection experiments reported here confirm this hypothesis by demonstrating that class I transcripts can induce ventral structures on the dorsal side of the wild-type embryo or in an embryo that lacks the activity of the upstream gene easter.

When the class I transcripts are injected locally into $\mathrm{Tl}^{-}$or $e a^{-}$embryos, ventral structures differentiate at the injection site and a complete, normally proportioned dorsal-ventral pattern can develop (Fig. $3 \mathrm{H}$ ). The asymmetric dorsal-ventral pattern of the injected $e a^{-}$embryos contrasts with the dorsoventrally symmetric lateralized embryos produced by $T l^{1}-e a^{-}$double-mutant females (Anderson et al. 1985b). This difference could be accounted for if in $T l^{1}-e a^{-}$embryos the $T l^{1}$ product is constitutively active at all dorsal-ventral positions, producing a lateralized phenotype, while in $e a^{-}$embryos injected with a high concentration of $T l^{1}$ RNA, the constitutively active, nondiffusing $T I^{1}$ product is confined to one side of the embryo and can then generate a normal, asymmetric pattern.

The $T 1^{1}-e a^{+}$embryo is ventralized and has normal polarity, with a ventral furrow forming on the normal ventral side. The asymmetry seen in the $\mathrm{Tl}^{1}\left(e a^{+}\right) \mathrm{em}-$ bryo must be the result of an enhancement of the activity of the $T l^{1}$ product above its baseline constitutive level by a ventral signal that depends on easter activity. This kind of enhancement was seen in the $T l^{1}$ transcript injections, where the activity of the $T I^{1}$ product was approximately fivefold lower in the absence of $e a^{+}$(Table 1). Thus, in the wild-type embryo it is likely that asymmetric activation of the uniformly distributed Toll product by an easter-dependent upstream ventral signal gives rise to the normal pattern.

It is interesting that two very different means of achieving localized Toll activity, local activation by an upstream signal or local injection of a nondiffusible, constitutively active receptor, can both result in a normal dorsal-ventral pattern. It seems likely that the spatial distribution of active Toll molecules is different in the two cases, suggesting that mechanisms act downstream of Toll to regulate proportioning of the dorsal-ventral pattern.

\section{Truncated class II dominant products activate the wild-type Toll protein in trans}

The class II dominant alleles of Toll encode stable truncated polypeptides (Fig. 5) that lack both the transmembrane and cytoplasmic domains and are therefore presumably secreted into the extracellular perivitelline 
space. The truncated, secreted products of the class II alleles are active only in the presence of both the transmembrane Toll protein and the products of the genes upstream of Toll. Thus, the amino-terminal 464 amino acids of Toll must include a domain that, together with the normal upstream gene products, can control the activity of wild-type Toll protein.

It is possible to explain the phenotypes of the class II alleles by three different kinds of interactions: The amino-terminal domain of Toll could bind the transmembrane Toll, it could bind to an inhibitor of Toll, or it could bind to an activator of Toll. In the first model, the truncated Toll proteins could increase the activity of the wild-type Toll gene product by interacting directly with the wild-type transmembrane protein. Many transmembrane signal transducers require ligand-induced multimerization to be activated (Ullrich and Schlessinger 1990). If Toll activation also requires multimerization, the truncated molecules may facilitate this process. In a second model, the activity of the full-length Toll protein is increased because truncated Toll molecules sequester an inhibitor of wild-type Toll. This model predicts that there is an upstream inhibitor of Toll, but no such molecule has been identified genetically. In a third model, the dominant ventralizing activity of class II alleles depends on the secretion and solubility of their gene products. If the upstream gene products create a diffusible asymmetric activating signal on the ventral side of the embryo, truncated Toll molecules could bind to the activator and promote its diffusion to the dorsal side of the embryo, where the activator could be released to activate wild-type Toll protein.

Biochemical and molecular genetic evidence indicates that truncated and secreted forms of many cell-surface receptors are produced naturally (Goodwin et al. 1990). The truncated receptors could decrease receptor activity by competing for ligand with the transmembrane form or by interfering with the signal transduction process (Basu et al. 1989; Taira et al. 1989|. However, in contrast with these dominant negative interactions, the Toll class II alleles indicate that a truncated protein can induce the ectopic activity of a full-length receptor.

\section{The Toll cytoplasmic domain: Homology to the IL-1R}

The sequence similarity between the cytoplasmic domains of Toll and the IL-1R and the mapping of the lossof-function alleles of Toll to the region of similarity suggest the hypothesis that Toll and the IL-1R transmit their signals by similar mechanisms. The mechanism of signal transduction by the IL-1R is not yet clear, although studies have implicated increases in cAMP or diacylglycerol as steps in the pathway (Rosoff et al. 1988; Shirakawa et al. 1988; Zhang et al. 1988). A number of new recessive Toll alleles that have been isolated recently (N. Machin, pers. comm.) may help to evaluate the significance of the sequence similarity and to define functional regions within both cytoplasmic domains.

The potential homology between Toll and the IL-1R is particularly tantalizing because the proteins that act downstream of these two transmembrane proteins may act in similar signal transduction pathways. Toll indirectly controls the activity of the dorsal protein by controlling its nuclear localization (Roth et al. 1989; Rushlow et al. 1989; Steward 1989). Similarly, in some cell lines, IL-1 causes the transcription factor NF- $\mathrm{kB}$ to be translocated from the cytoplasm into the nucleus, where it is then active (Shirakawa et al. 1989). The sequence similarity of dorsal to the DNA-binding p50 subunit of NF- $\mathrm{KB}$ (Ghosh et al. 1990; Kieran et al. 1990), the regulation of both transcription factors at the level of nuclear translocation, and the sequence similarity of Toll and the IL-1R suggest that the intermediates in the two pathways may be also similar.

\section{Materials and methods}

\section{Mutant alleles}

Most Toll alleles have been described previously (Anderson et al. 1985b; Gerttula et al. 1988; Erdélyi and Szabad 1989|. The dominant alleles $T 1^{D B 1}$ (Dominant Berkeley 1), $T 1^{D B 2}$, and $T 1^{D B 3}$ were fortuitously isolated in $\mathrm{F}_{2}$ screens for maternal-effect mutations (S. Wasserman, D. Morisato, and K.V. Anderson, unpubl.).

\section{Sequencing of mutant alleles}

The sequences of the Toll alleles were determined by the dideoxy chain-termination technique (Sanger 1977), using the Sequenase system (U.S. Biochemical Corporation). The sequences of the parental chromosomes of all the Toll alleles, with the exception of $T 7^{226}, T 1^{1}, T 1^{10 b}$, and $T T^{2 b}$, were also determined. Genomic DNA, including the Toll open reading frame and a 106-bp intron between cDNA nucleotides 1793 and 1794 (Hudson 1989), was sequenced by using oligonucleotide primers spaced every $200 \mathrm{bp}$.

Two mutant Toll alleles were cloned from genomic libraries. The $T I^{84 c}$ allele was cloned from an EMBL 4 library of partial Sau3A-digested genomic DNA from $T l^{84 c} / \mathrm{TM} 3$ flies. The $T l^{9 \mathrm{Q}}$ allele was cloned from a $\lambda F I X$ (Stratagene) library of XhoI-digested genomic DNA obtained from $T 1^{9 Q} / \mathrm{TM} 3$ flies. Alleles of Toll cloned from the TM3 balancer chromosome were identified by the presence of a polymorphic BamHI restriction site that is not present in the $T l^{84 c}$ and $T l^{9 Q}$ alleles. The open reading frames of these two dominant alleles were sequenced completely.

The remaining alleles were sequenced from mutant genomic DNA amplified by the polymerase chain reaction (PCR) (Saiki et al. 1988). The recessive alleles were sequenced from PCR-amplified DNA that was cloned into pBluescript (Stratagene). The 3.4-kb Toll open reading frame-containing DNA was amplified in two fragments from DNA obtained from flies homozygous for each recessive allele. The entire open reading frame of each of the recessive alleles was sequenced. Mutant sequences were confirmed by directly sequencing PCR products. The sequences of $T 1^{10 b}, T l^{1}, T l^{D B 1}, T l^{S B}, T l^{2 B}, T l^{D B 2}$, and $T 1^{D B 3}$ were obtained by directly sequencing DNA amplified from genomic DNA isolated from flies carrying the mutant alleles in trans to a deficiency $\left(T 1^{10 b}, T 1^{1}\right.$, and $\left.T 1^{D B 1}\right)$ or in trans to a balancer (TM3) chromosome $\left(T l^{2 b}, T l^{5 B}, T l^{D B 2}\right.$, and $\left.T l^{D B 3}\right) . T l^{10 b}$ and $T l^{1}$ were sequenced from nucleotide 2535 to nucleotide $3040, T 1^{D B 1}$ and $T 1^{2 b}$ were sequenced from nucleotide 2285 to nucleotide 2475 , $T l^{D B 2}$ and $T l^{D B 3}$ were sequenced from nucleotide 2555 to 2872 . 
$T I^{5 B}$ was sequenced from nucleotide 1248 to nucleotide 2451 and from nucleotide 2540 to 2930 .

\section{Transcripts of mutant alleles}

A full-length, wild-type Toll cDNA was constructed (C. Hashimoto, unpub1.) in a pGEM-2 vector (Promega). cDNAs including the point mutations in the dominant alleles $T l^{1}$ and $T 1^{10 b}$ were constructed by replacing a PflmI-StuI restriction fragment in the wild-type cDNA with a fragment (nucleotide 2800-3483 in the cDNA sequence) amplified from mutant DNA by PCR. The reconstructed dominant alleles were sequenced over the $P f l m I-S t u I$ restriction fragment to ensure that the DNA did not contain any PCR-derived artifacts.

A Toll allele containing a stop codon in the extracellular domain $\left(T T^{\text {trunc1 }}\right)$ was constructed by inserting an $X b a I$ linker (New England Biolabs) containing stop codons in all three reading frames into the open reading frame of the Toll cDNA. The pGEM-2 vector containing the full-length, wild-type cDNA was linearized with StuI, which cuts in the cytoplasmic domain of Toll. To place the linkers in the extracellular domain of Toll, ExoIII deletions were performed on this linearized plasmid essentially as described previously (Henikoff 1987). Nonphosphorylated $X b a I$ linkers were ligated to the deleted plasmids, and the ligation reactions were precipitated to remove unligated linkers. The ligated DNA was resuspended in $40 \mathrm{~mm}$ Tris- $\mathrm{HCl}$ (pH 7.5), $20 \mathrm{mM} \mathrm{MgCl}_{2}$, and $50 \mathrm{~mm} \mathrm{NaCl}$, heated to $65^{\circ} \mathrm{C}$, and cooled slowly to allow the free ends to anneal. This recircularized DNA was used to transform Escherichia coli MC1061 cells. $T 1^{\text {trunc1 }}$ contains an $X b a I$ linker after nucleotide 2559 in the Toll cDNA sequence and an 1825-bp deletion from nucleotide 2559 to 4384 .

\section{Transcript injection}

pGEM-2 templates were linearized and SP6 transcripts were generated essentially as described (Krieg and Melton 1987), in the presence of $500 \mu \mathrm{M}$ TTP, CTP, ATP (Pharmacia), cap analog $\left({ }^{5} \mathrm{GpppG}^{3}\right.$; Pharmacia), $50 \mu \mathrm{M}$ GTP, and $2.5 \mathrm{nM}\left[\alpha^{-32} \mathrm{P}\right] \mathrm{CTP}$, at $800 \mathrm{Ci} / \mathrm{mmole}$ (Amersham). After $2 \mathrm{hr}$, the reaction mixture was diluted with one volume of $100 \mathrm{mM} \mathrm{NaCl}, 30 \mathrm{~mm}$ EDTA, 20 $\mathrm{mM}$ Tris $(\mathrm{pH} 7.5)$, and $1 \%$ SDS and passed over a $1-\mathrm{ml}$ Sephadex G-50 spin column, equilibrated in $0.3 \mathrm{M}$ sodium acetate and $0.1 \%$ SDS, to remove unincorporated nucleotides. The reaction was then extracted with phenol and precipitated twice with ethanol to remove residual SDS. Transcripts were resuspended in injection buffer (Anderson and Nüsslein-Volhard 1984). The concentration of the transcribed RNA was determined by calculating the percentage incorporation of the radiolabeled CTP.

\section{Protein analysis}

Staged 0- to 4-hr embryos were collected, dechorionated, and homogenized in a solution of $10 \mathrm{mM}$ Tris- $\mathrm{HCl}(\mathrm{pH} 8.0)$, and 1 mM EDTA. Wild-type embryo extracts were obtained from Oregon-R flies. $T l^{-}$embryos were obtained from $\mathrm{Df}(3 \mathrm{R}) \mathrm{TI}^{\mathrm{rOXB}}$ / Df(3R)Tl $1^{9 Q R X}$ females, which make no Toll RNA (Hashimoto et al. 1988). Ventralized embryos were collected from $T 1^{\text {classII }} / \mathrm{Tl}^{+}$ flies. Extracts were centrifuged at $10,000 \mathrm{~g}$ for $10 \mathrm{~min}$ to remove insoluble material, and $100 \mu \mathrm{g}$ of protein was loaded per lane. Proteins were blotted as described (Hashimoto et al. 1991). Blots were probed with a $1: 40$ dilution of affinity-purified rabbit polyclonal primary antibody raised against the amino-terminal portion of Toll (Hashimoto et al. 1991), and 1:10,000 dilution of HRP-linked goat-anti-rabbit secondary antibody (Bio-Rad). Toll protein was visualized by using an ECL kit (Amersham).

\section{Acknowledgments}

We thank Arend Sidow for advice concerning direct sequencing of PCR products and Chris Kaiser for help in sequence analysis. We also thank Becky Chasan, Chip Ferguson, Linda Hicke, Bruce Kimmel, Sylvia Sanders, and Mike Simon and the members of the Anderson laboratory for helpful comments on the manuscript. This work was supported by grants from the National Institutes of Health (GM 35437), the National Science Foundation (DCB 8452030), and the American Cancer Society (NP726) to K.V.A.

The publication costs of this article were defrayed in part by payment of page charges. This article must therefore be hereby marked "advertisement" in accordance with 18 USC section 1734 solely to indicate this fact.

\section{References}

Anderson, K.V. and C. Nüsslein-Volhard. 1984. Information for the dorsal-ventral pattern of the Drosophila embryos is stored as maternal mRNA. Nature 311: 223-227.

- 1986. Dorsal-group genes of Drosophila. In Gametogenesis and the early embryo (ed. J. Gall), pp. 177-194. Alan R. Liss, New York.

Anderson, K.V., L. Bokla, and C. Nüsslein-Volhard. 1985a. Establishment of dorsal-ventral polarity in the Drosophila embryo: The induction of polarity by the Toll gene product. Cell 42: 791-798.

Anderson, K.V., G. Jürgens, and C. Nüsslein-Volhard. 1985b. Establishment of dorsal-ventral polarity in the Drosophila embryo: Genetic studies on the role of the Toll gene product. Cell 42: 779-789.

Basu, A., M. Raghunath, S. Bishayee, and M. Das. 1989. Inhibition of tyrosine kinase activity of the epidermal growth factor (EGF) receptor by a truncated receptor form that binds to EGF: Role for interreceptor interaction in kinase regulation. Mol. Cell. Biol. 9: 671-677.

Chasan, R. and K.V. Anderson. 1989. The role of easter, an apparent serine protease, in organizing the dorsal-ventral pattern of the Drosophila embryo. Cell 56: 391-400.

DeLotto, R. and P. Spierer. 1986. A gene required for the specification of dorsal-ventral pattern in Drosophila appears to encode a serine protease. Nature 323: 688-692.

Erdélyi, M. and J. Szabad. 1989. Isolation and characterization of dominant female sterile mutations of Drosophila melanogaster. I. Mutations on the third chromosome. Genetics 122: $111-127$.

Gerttula, S., Y. Jin, and K.V. Anderson. 1988. Zygotic expression and activity of the Drosophila Toll gene, a gene required maternally for embryonic dorsal-ventral pattern formation. Genetics 119: 123-133.

Ghosh, S., A.M. Gifford, L.R. Riviere, P. Tempst, G.P. Nolan, and D. Baltimore. 1990. Cloning of the p50 DNA binding subunit of NF-кB: Homology to rel and dorsal. Cell 62: 1019-1029.

Goodwin, R.G., D. Friend, S.F. Ziegler, R. Jerzy, B.A. Falk, S. Gimpel, D. Cosman, S.K. Dower, C.J. March, A.E. Namen, and L.S. Park. 1990. Cloning of the human and murine interleukin-7 receptors: Demonstration of a soluble form and homology to a new receptor superfamily. Cell 60: 941-951.

Greenwald, I. and G. Seydoux. 1990. Analysis of gain-of-function mutations of the lin-12 gene of Caenorhabditis elegans. Nature 346: 197-199.

Hashimoto, C., K.L. Hudson, and K.V. Anderson. 1988. The Toll gene of Drosophila, required for dorsal-ventral embryonic polarity, appears to encode a transmembrane protein. Cell 
52: 269-279.

Hashimoto, C., S. Gerttula, and K.V. Anderson. 1991. Plasma membrane localization of the Toll protein in the syncytial Drosophila embryo: Importance of transmembrane signaling for dorsal-ventral pattern formation. Development (in press).

Henikoff, S. 1987. Unidirectional digestion with exonuclease III in DNA sequence analysis. Methods Enzymol. 155: 156165.

Hickey, M.J., S.A. Williams, and G.J. Roth. 1989. Human platelet glycoprotein IX: An adhesive prototype of leucine-rich glycoproteins with flank-center-flank structures. Proc. Natl. Acad. Sci. 86: 6773-6777.

Hudson, K.L. 1989. Ph.D. thesis. University of California, Berkeley.

Keith, F.J. and N.J. Gay. 1990. The Drosophila membrane receptor Toll can function to promote cellular adhesion. $E M B O$ J. 9: 4299-4306.

Kieran, M., V. Blank, F. Logeat, J. Vanderkerckhove, F. Lottspeich, O. Le Bail, M.B. Urban, P. Kourilsky, P.A. Baeuerle, and A. Israël. 1990. The DNA binding subunit of NF-kB is identical to factor $\mathrm{KBF} 1$ and homologous to the rel oncogene product. Cell 62: 1007-1018.

Klein, R., L.F. Parada, F. Coulier, and M. Babacid. 1989. trkB, a novel tyrosine protein kinase receptor expressed during mouse neural development. EMBO J. 8: 3701-3709.

Krantz, D.E. and S.C. Zipursky. 1990. Drosophila chaoptin, a member of the leucine-rich repeat family, is a photoreceptor cell-specific adhesion molecule. EMBO J. 9: 1969-1977.

Krieg, P.A. and D.A. Melton. 1987. In vitro RNA synthesis with SP6 RNA polymerase. Methods Enzymol 155: 397-415.

Lopez, J.A., D.W. Chung, K. Fujikawa, F.S. Hagen, T. Papayannopoulou, and G.J. Roth. 1987. Cloning of the $\alpha$ chain of human platelet glycoprotein Ib: A transmembrane protein with homology to leucine-rich $\alpha_{2}$-glycoprotein. Proc. Natl. Acad. Sci. 84: 5615-5619.

Lopez, J.A. , D.W. Chung, K. Fujikawa, F.S. Hagen, E.W. Davie, and G.J. Roth. 1988. The $\alpha$ and $\beta$ chains of human platelet glycoprotein Ib are both transmembrane proteins containing a leucine-rich amino acid sequence. Proc. Natl. Acad. Sci. 85: 2135-2139.

McFarland, K.C., R. Sprengel, H.S. Phillips, M. Köhler, N. Rosemblit, K. Nikolics, D.L. Segaloff, P.H. Seeburg. 1989. Lutropin-choriogonadotropin receptor: An unusual member of the G protein-coupled receptor family. Science 245: 494 499.

Miyata, T., S. Miyazawa, and T. Yasonaga. 1979. Two types of amino acid substitution in protein evolution. /. Mol. Evol. 12: 219-236.

Rice, T.B. 1973. Ph.D. thesis. Yale University, New Haven, Ct.

Rosoff, P.M., N. Savage, and C.A. Dinarello. 1988. Interleukin-1 stimulates diacylglycerol production in $\mathrm{T}$ lymphocytes by a novel mechanism. Cell 54: 73-81.

Roth, S., D. Stein, and C. Nüsslein-Volhard. 1989. A gradient of nuclear localization of the dorsal protein determines dorsoventral pattern in the Drosophila embryo. Cell 59: 11891202

Rushlow, C., M. Frasch, H. Doyle, and M. Levine. 1987. Maternal regulation of zerknüllt: A homoeobox gene controlling differentiation of dorsal tissues in Drosophila. Nature 330: $583-586$

Rushlow, C.A., K. Han, J.L. Manley, and M. Levine. 1989. The graded distribution of the dorsal morphogen is initiated by selective nuclear transport in Drosophila. Cell 59: 11651177.

Saiki, R.K., U.B. Gyllensten, and H.A. Erlich. 1988. The polymerase chain reaction. In Genome analysis: A practical ap- proach (ed. K.E. Davies), pp. 141-152. IRL Press, Oxford.

Sanger, F., S. Nicklen, and A.R. Coulson. 1977. DNA sequencing with chain- terminating inhibitors. Proc. Natl. Acad. Sci. 74: 5463-5467.

Schüpbach, T. and E. Wieschaus. 1989. Female sterile mutations on the second chromosome of Drosophila melanogasier. I. Maternal effect mutations. Genetics. 121:101-117.

Shirakawa, F., U. Yamashita, M. Chedid, and S.B Mizel. 1988. Cyclic AMP-An intracellular second messenger for interleukin 1. Proc. Natl. Acad. Sci. 85:8201-8205.

Shirakawa, F., M. Chedid, J. Suttles, B.A. Pollok, and S.B. Mizel. 1989. Interleukin 1 and cyclic AMP induce $\kappa$ immunoglobulin light-chain expression via activation of an NF-kB-like DNA-binding protein. Mol. Cell. Biol. 9: 959-964.

Sims, J.E., R. Acres, C.E. Grubin, C.J. McMahan, J.M. Wignall, C.J. March, and S.K. Dower. 1989. Cloning of the interleukin 1 receptor from human T cells. Proc. Natl. Acad. Sci. 86: 8946-8950.

Sims, J.E., C.J. March, D. Cosman, M.B. Widmer, H.R. MacDonald, C.J. McMahan, C.E. Grubin, J.M. Wignal, J.L. Jackson, S.M. Call, D. Friend, A.R. Alpert, S. Gillis, D.L. Urdal, and S.K. Dower. 1988. cDNA expression cloning of the IL-1 receptor, a member of the immunoglobulin superfamily. Science 241: 585-589.

Steward, R. 1989. Relocalization of the dorsal protein from the cytoplasm to the nucleus correlates with its function. Cell 59: 1179-1188.

Steward, R., S.B. Zusman, L.H. Huang, and P. Schedl. 1988. The dorsal protein is distributed in a gradient in early Drosophila embryos. Cell 55: 487-495.

Taira, M., M. Taira, N. Hashimoto, F. Shimada Y. Suzuki, A. Kanatsuka, F. Nakamura, Y. Ebina, M. Tatibana, H. Makino, and S. Yoshida. 1989. Human diabetes associated with a deletion of the tyrosine kinase domain of the insulin receptor. Science 245: 63-68.

Takahashi, N., Y. Takahashi, and F.W. Putnam. 1985. Periodicity of leucine and tandem repetition of 24-amino acid segment in the primary structure of leucine-rich $\alpha_{2}$-glycoprotein of human serum. Proc. Natl. Acad. Sci. 82: 19061910.

Ullrich, A. and J. Schlessinger. 1990. Signal transduction by receptors with tyrosine kinase activity. Cell 61: 203-212.

Yochem, J., K. Weston, and I. Greenwald. 1988. The Caenorhabditis elegans lin-12 gene encodes a transmembrane protein with overall similarity to Drosophila Notch. Nature 335: $547-550$.

Zhang, Y., J.-X. Lin, Y.K. Yip, and J. Vilček. 1988. Enhancement of cAMP levels and of protein kinase activity by tumor necrosis factor and interleukin 1 in human fibroblasts: Role in the induction of interleukin 6. Proc. Natl. Acad. Sci. 85: 6802-6805. 


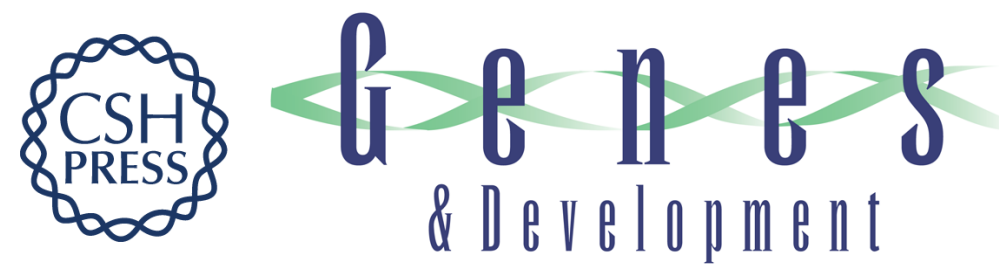

\section{Dominant and recessive mutations define functional domains of Toll, a transmembrane protein required for dorsal-ventral polarity in the Drosophila embryo.}

D S Schneider, K L Hudson, T Y Lin, et al.

Genes Dev. 1991, 5:

Access the most recent version at doi:10.1101/gad.5.5.797

References This article cites 40 articles, 16 of which can be accessed free at: http://genesdev.cshlp.org/content/5/5/797.full.html\#ref-list-1

License

Email Alerting Service

Receive free email alerts when new articles cite this article - sign up in the box at the top right corner of the article or click here.

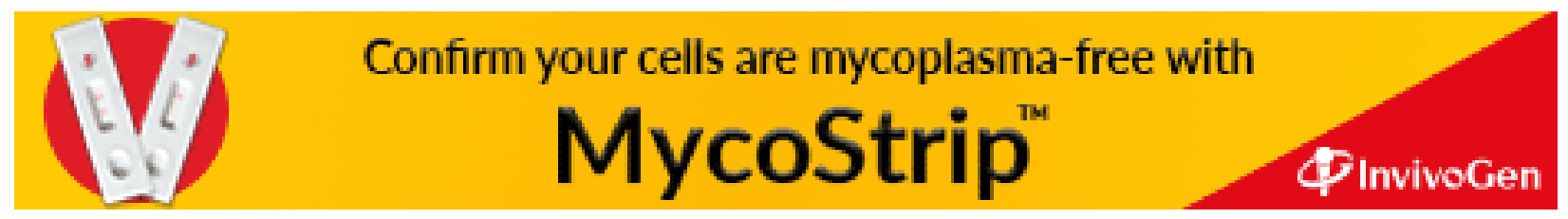

